\title{
Monitoring of trace organic air pollutants - a developing country perspective
}

\author{
P. B. C. Forbes ${ }^{1} \&$ E. R. Rohwer ${ }^{2}$ \\ ${ }^{I}$ Natural Resources and the Environment, CSIR, South Africa \\ ${ }^{2}$ Department of Chemistry, University of Pretoria, South Africa
}

\begin{abstract}
Air pollutants arise both from natural sources and from various anthropogenic activities, and are of concern due to their environmental impacts, including human health effects. In developing countries, atmospheric monitoring has largely focused on inorganic pollutants, such as sulphur dioxide, nitrogen oxides and ozone. Organic air pollutants, however, are monitored infrequently, because of factors such as the cost of equipment required; necessary expertise of monitoring personnel; and the trace levels at which such pollutants are usually present in the atmosphere. This is of concern since organic air pollutants, such as polycyclic aromatic hydrocarbons (PAHs) and dioxins, are emitted from combustion processes, which are often employed for domestic heating and cooking purposes in developing countries.

This paper focuses on the current status of organic air pollutant monitoring in southern Africa, and discusses developments in this regard. Screening methods and monitoring of indicator compounds, which allow for more widespread sampling and analysis of samples for spatial and temporal trend determinations, are discussed. A laser induced fluorescence (LIF) technique, for example, has been developed by the authors, based on sampling onto a novel silicone rubber trap. This will allow for the rapid screening of air samples for the presence of PAHs, prior to comprehensive, quantitative analysis of samples of interest by gas chromatography-mass spectrometry (GC-MS) (particularly those with PAH levels above background concentrations). LIF provides sufficient selectivity for a screening procedure, without the need for sample clean-up and separation processes prior to analysis. The technique also lends itself to real-time monitoring and "chemical fingerprinting" via the fluorescence spectra obtained.
\end{abstract}

Keywords: trace organic air pollutants, developing countries, combustion emissions, polycyclic aromatic hydrocarbons, dioxins, laser induced fluorescence. 


\section{Introduction}

\subsection{Air pollution in developing countries}

The air quality of developing countries is deteriorating due to industrial development, economic growth and large-scale migration of rural residents to urban areas. Consequences of this include a decline in food security, an increase in respiratory related illnesses, and a degradation of both the quality of life and the environment [1]. Comprehensive and reliable air monitoring data is key to the improvement of air quality, as without this information it is impossible to identify and apportion emission sources [2].

Whilst it is acknowledged that significant progress has been made in organic air pollutant monitoring in many developing countries in Asia and South America, this paper focuses on southern Africa. The geographic delineation for the region was used, i.e. the portion of Africa south of the Cunene and Zambezi rivers. This incorporates the countries of Botswana, Lesotho, Namibia, Mozambique, South Africa, Swaziland and Zimbabwe, as shown in Figure 1.

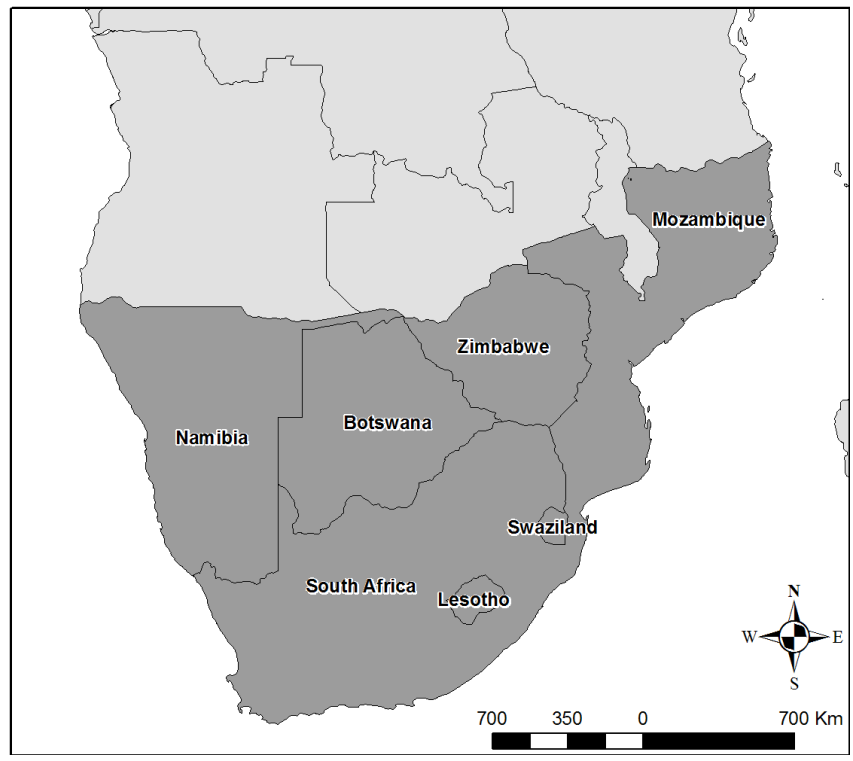

Figure 1: $\quad$ Southern African countries.

In addition to industrial emissions, major sources of air pollutants in developing countries include dependence on fossil fuels, and increasing traffic densities in urban areas, mainly involving an aged vehicle fleet without catalytic converters. Besides the relatively commonly monitored inorganic pollutants which are released from these combustion processes, for example, nitrogen oxides, sulphur dioxide and carbon dioxide; organic pollutants may also be released in the gaseous form or associated with particles. Hydrocarbons and 
polycyclic aromatic hydrocarbons (PAHs) are examples of such pollutants, as are polychlorinated dibenzodioxins and furans which may be generated when chlorinated material is combusted. Although the organic pollutants would generally be present at lower concentrations than the inorganic species, they are nevertheless of environmental significance due to their potential impacts (including health effects) at low levels.

\subsection{Hindrances to air pollutant monitoring in developing countries and means by which these are being addressed}

Organic air pollutant monitoring has been minimal in many developing countries to date, particularly those on the African continent. This is due to a number of reasons, some of which are the result of socio-political priorities. In addition, a lack of resources is often the most prominent hindrance, where funding, skilled human capital, and suitable equipment may be unavailable.

Various initiatives have been established in order to address these issues. For example, the Air Pollution Information Network for Africa (APINA) is a subSaharan regional network of scientists, policy-makers and non-governmental organizations, and its member countries include Botswana, Mozambique, South Africa and Zimbabwe. APINA aims to address air pollution problems, as part of the RAPIDC (Regional Air Pollution in Developing Countries) programme. RAPIDC is funded by the Department of Infrastructure and Economic Cooperation (INEC) of SIDA, the Swedish International Development Cooperation Agency and includes initiatives in both Asia and Africa [3].

The Southern and Eastern Africa Network of Analytical Chemists (SEANAC) was established to assist with capacity building and collaboration in the region, specifically in the areas of health, food security and environmental monitoring. One of the problems cited as being faced by African analytical chemists is that many of them received training abroad in techniques which are much more appropriate to the developed world [4].

The Organisation for Economic Co-operation and Development (OECD) has investigated the impact of monitoring equipment on air quality management in developing countries [2]. Capacity building is achieved through case studies, where participant countries are assisted with monitoring equipment and training. The case studies conducted to date do not include southern African countries, and have focused on inorganic pollutants, with the exception of one study involving fuel testing in India, where PAHs were monitored.

\section{Overview of organic air pollutant monitoring in southern Africa}

It is relevant to consider southern Africa as a region in terms of air quality, as the climate and air circulation of the region south of northern Angola is dominated by a gyre centred on Botswana. The air rotates anti-clockwise, completing one revolution approximately every week and the gyre thus formed remains in place for several weeks, particularly in winter, which leads to a build up of various 
trapped atmospheric pollutants, resulting in deterioration in visibility and air quality over parts of the subcontinent [5].

Monitoring activities are largely driven by legislation, thus an overview of the existing air quality legislation pertaining to the region is included in this section. It is generally accepted that environmental legislation in many African countries is outdated, or is poorly enforced due to a lack of capacity or poor institutional organisation. In some cases, more modern legislation still allows industries which were in existence before promulgation to continue operating outdated equipment, even if this leads to excessive pollution.

Some monitoring is undertaken by local government municipalities, industries, and research institutions in the different countries of interest, but in most cases such monitoring is currently restricted to inorganic air pollutants. Publicly accessible published organic air pollutant monitoring activities, conducted prior to 2007, are summarised in the following sections. It is acknowledged that additional monitoring may have taken place for the purpose of Environmental Impact Assessments (EIAs), for example.

\subsection{Botswana}

Routine air quality monitoring began in Botswana in the mid 1970s, upon the promulgation of the Atmospheric Pollution Prevention Act in 1971. Continuous monitoring of hydrocarbons has been conducted in Botswana at one site since 1999 [6], but most of the monitoring sites focus on inorganics $\left(\mathrm{SO}_{2}, \mathrm{NO}_{\mathrm{x}}, \mathrm{O}_{3}\right.$, $\mathrm{CO}$ and particulate matter) and associated meteorological data. Ambient air quality objectives for Botswana do not include organic air pollutants. A National Environmental Laboratory was established in 2002, however, which has the capabilities to analyse organic pollutants [1].

\subsection{Lesotho}

The Environment Act 2001 provides for the management of the environment and all natural resources of Lesotho. The Act makes provision for the establishment of environmental quality standards and environmental monitoring, but it is unclear as to whether such provisions have been enacted [7].

\subsection{Mozambique}

Mozambique has an Environmental Law of 1997, but few air pollutant monitoring studies have been conducted in this country [1].

\subsection{Namibia}

The Namibian Directorate of Environmental Affairs has noted that air pollution is a less serious problem than in many other countries, although the need to update the environmental legislation to enable effective law enforcement is acknowledged [8]. No systematic air quality monitoring had occurred in Namibia, as of 2001 [6]. 


\subsection{South Africa}

A new era in air quality management in South Africa began with the promulgation of the National Environmental Management: Air Quality Act in 2004 (Act No. 39 of 2004) (AQA), which replaced the Air Pollution Prevention Act of 1965 (Act No. 45 of 1965). This has resulted in a shift from an emission control focus to an airshed approach, which culminated in the establishment of national standards for permissible ambient concentrations of air pollutants [9].

This has implications in terms of air quality monitoring, as methods are required which are suitable for monitoring pollutants at ambient concentrations, which are generally lower than emission levels. Alternative methods, which allow for pre-concentration of analytes of interest and which have lower detection limits, are therefore of importance. Sampling methods employed in ambient and emission air monitoring are also different. Development of the capacity and capabilities to perform ambient air monitoring (as well as in air quality management) is therefore receiving attention in South Africa, particularly at local government level.

At present, benzene is the only organic air pollutant for which ambient standards have been set (an annual average of $5 \mu \mathrm{g} \cdot \mathrm{m}^{-3}$ ), although the AQA makes provision for the Minister of Environmental Affairs and Tourism to make notice of additional air pollutants, as necessary.

In terms of monitoring, local municipalities in South Africa currently monitor Volatile Organic Compounds (VOCs) (specifically benzene, toluene, ethylbenzene and xylenes) at nine sites across three provinces. Methane is also monitored at four stations in two provinces, one of which is the WMO Global Atmospheric Watch (GAW) site at Cape Point [10]. Non-methane hydrocarbons are also monitored monthly at the GAW site, by means of grab sampling into canisters which are analysed in Europe. These samples have yielded interesting results in the context of biomass burning episodes, for example [11].

VOCs have been studied in various contexts, including that of emissions from spontaneous combustion of coal [12] and the Cape Town brown haze, which forms in winter months under inversion conditions [13].

In addition to monitoring campaigns, fundamental research has been conducted in South Africa in terms of novel means of sampling and analysing organic air pollutants. Ortner and Rohwer [14] developed thick film multichannel silicone rubber traps, which have been applied in semi-volatile organic air pollutant sampling. These traps serve as pre-concentrators and can be thermally desorbed for $\mathrm{GC}$ analysis, thereby negating the need for solvent extraction and concentration. Burger et al [15] has also developed a high capacity, polydimethylsilicone rubber sample enrichment probe (SEP), which can be thermally desorbed for GC analysis. A novel thermal modular array for comprehensive two-dimensional gas chromatography has also been produced by these researchers [16].

\subsection{Swaziland}

Air Pollution Control Regulations have been drafted for Swaziland, which include air quality objectives for a number of inorganic air pollutants only [17]. 


\subsection{Zimbabwe}

Zimbabwe has an Atmospheric Pollution Control Act (No. 33 of 1971 as amended by Act No. 22 of 2002) and Atmospheric Pollution Prevention Regulations of 1975. The Environmental Management Act was enacted in December 2002, which will repeal the existing air legislation in due course, and will provide for the establishment of Air Quality Standards [1].

Some random air monitoring studies have been conducted in Zimbabwe, and the Air Pollution Control Unit of the City of Harare Health Department has carried out routine air pollution monitoring of $\mathrm{SO}_{2}, \mathrm{NO}_{2}$ and soot at eight sites over the past 20-30 years. Other parameters which have been monitored include methane and VOCs, in addition to inorganic analytes $\left(\mathrm{Pb}, \mathrm{NH}_{3}, \mathrm{HCl}\right.$ and particulate matter) [1].

\subsection{Other African studies}

Few published organic air pollutant monitoring campaigns have been conducted in other African countries, such as the monitoring of PAHs from charcoal burning in Kenya (using liquid chromatography with fluorescence detection) [18]. The majority of these studies were carried out in collaboration with developed countries, which assisted primarily with analyses. Studies of organic pollutants, particularly pesticides, in other environmental media [19], also indicate that there is some existing capacity that could provide a basis for air monitoring. An example is the determination of PAHs in surface runoff and sediments in Nigeria [20].

\subsection{Involvement of southern Africa in international conventions}

In terms of organic pollutant monitoring, the Stockholm Convention on Persistent Organic Pollutants (POPs) is of relevance. The majority of southern African countries have become signatories to this convention, and as such have a responsibility to manage and monitor POPs. Existing monitoring progammes, activities and datasets have recently been compiled [21], and are summarised in Table 1. Although concentrations of POPs were determined in ambient air in Durban, South Africa, all analyses were performed in the USA [22]. It is evident that capabilities in the region require further development.

\subsection{Southern African air monitoring campaigns}

The Southern Africa Fire-Atmosphere Research Initiative of 1992 (SAFARI -92) and the Southern African Regional Science Initiative of 2000 (SAFARI 2000) provided scientists in the region with the opportunity to participate in large research projects with international experts. SAFARI-92 investigated the role of savanna fires in atmospheric chemistry, climate and ecology, where organic monitoring included $\mathrm{CH}_{4}$ and non-methane hydrocarbons [23]. More than 150 scientists from 14 countries were involved, including the southern African countries of Botswana, Namibia, South Africa, Swaziland and Zimbabwe. 
Table 1: $\quad$ Existing national monitoring programmes, activities and datasets for southern African countries [21].

\begin{tabular}{|l|l|}
\hline \multicolumn{1}{|c|}{ Country } & \multicolumn{1}{|c|}{ Monitoring activities } \\
\hline Botswana & No data \\
\hline Lesotho & No data \\
\hline Mozambique & No data \\
\hline Namibia & Limited data \\
\hline South Africa & $\begin{array}{l}\text { No existing national POPs information gathering } \\
\text { activities. Academic research studies have been } \\
\text { conducted and published to assess POPs in various } \\
\text { media (Note: air was not included). }\end{array}$ \\
\hline Swaziland & No data \\
\hline Zimbabwe & Limited data \\
\hline
\end{tabular}

SAFARI 2000 addressed a broad range of phenomena related to land-atmosphere interactions and biogeochemical functioning of the southern African system. Here biogenic volatile organic compounds (BVOCs), VOCs, oxygenated VOCs, and semivolatile organic compounds (SVOCs) were also monitored [24].

\section{Use of alternative monitoring methods}

In light of the hindrances experienced in developing countries, as discussed under section 1.2, alternative monitoring methods to the standard comprehensive methods may be more appropriate. Such methods should be cost effective and simple, in order to allow for more widespread monitoring in the region. We now present a few options in this regard, with respect to organic air pollutants.

\subsection{Passive sampling}

Passive air samplers provide a useful means of monitoring in developing countries due to their simplicity, cost effectiveness and non-reliance on provision of a power source. Passive sampling may provide pre-concentration of analytes, thereby increasing analytical sensitivity, and may reduce or eliminate solvent consumption for sample preparation purposes. Sampling is based on diffusion or permeation of the analyte into the sampler, as reviewed by Seethapathy [25]. Passive samplers have found widespread application in airborne POPs monitoring, for example [26, 27].

Besides the use of evacuated canisters for passive organic air pollutant sampling, passive samplers of interest include solid phase microextraction (SPME), polyurethane foam based samplers, and samplers containing adsorbents such as graphitised charcoal or Tenax.

Studies have been conducted in South Africa to assess the chronic health impacts of exposure to VOCs (as well as naphthalene), by means of passive sampling, using $3 \mathrm{M}$ badges [28] and IVL passive samplers [29]. There is significant scope to implement passive sampling more widely in the field of 
organic air pollutant monitoring in southern Africa, and to utilise this technique for a wider range of organic analytes. It should be noted, however, that passive samplers may not provide the time resolution required in some monitoring campaigns, due to the relatively long sampling intervals usually employed (one to several weeks).

\subsection{Indicator compounds}

The monitoring of by-products (indicator compounds) of reaction pathways which generate the analyte of interest has been successfully utilised for various classes of chemicals. A relevant example is the monitoring of chlorobenzenes and chlorophenols as indicators for dioxins and furans, where correlation coefficients are used to relate the indicator compound concentrations to that of the target analyte [30]. Precursor compounds may be similarly utilised where intermediates in the synthesis of the target analyte are monitored.

The choice of indicator compound is based on the existence of a correlation with the target compound(s), ease of sampling, as well as other characteristics which simplify analysis, such as a higher concentration and existence of fewer congeners compared to the target analyte(s). The monitoring of indicator or precursor compounds for organic air pollutant monitoring therefore has great potential for application in developing countries, where resources and capacity are limited.

\subsection{Screening methods}

Screening methods find application in large sampling campaigns, in that numerous samples can be taken and analysed in order to determine whether more comprehensive analysis (by standard accepted methods) is required, such as samples which screen positive. A screening method should ideally be fast, simple and of low cost, yet meet the sensitivity and selectivity requirements of the application.

The authors have developed a laser induced fluorescence method as a screening tool for PAHs sampled onto multi-channel silicone rubber traps [14] by means of a portable GilAir sampling pump. An excimer laser (Lambda Physik EMG201) was used to optically pump a dye laser equipped with Rhodamine 6G dye. An intra-cavity grating allowed for wavelength tuneability over the gain bandwidth of the dye, and ensured a narrow bandwidth output $\left(0.1 \mathrm{~cm}^{-1}\right.$ at 495 $\mathrm{nm})$. In the case of naphthalene, for example, the $584 \mathrm{~nm}$ output beam was frequency doubled through second harmonic generation in a non-linear crystal, resulting in a $292 \mathrm{~nm}$ excitation laser wavelength $(\sim 500 \mu \mathrm{J}$ pulse energy in a 30 ns pulse, with a $5 \mathrm{~mm}$ spot size), which was directed onto the sample trap.

The fluorescence of the sample was optically collected, and resolved with a scanning double monochromator (Kratos, Schoeffel Instruments), equipped with a photomultiplier tube. Results were recorded on a PC linked to an oscilloscope (Tektronix TDS 360).

Different silicones were tested in order to minimize the background signal of the substrate and thereby enhance the detection limit of the method. The best 
results were obtained for the silicone which had the least aromatic moieties in the final product, as would be expected due to their chromophoric properties. Losses of naphthalene as a result of volatilization and photodegradation during laser irradiation were found to be less than $10 \%$ over a typical analysis period of 5 minutes. Initial experiments using standards yielded promising results, and the proof of concept of the method was demonstrated by the monitoring of PAHs arising from a sugar cane burn in KwaZulu Natal, South Africa.

The method is rapid, and has acceptably low limits of detection. LIF also provides sufficient selectivity for a screening procedure, without the need for sample clean-up and separation processes prior to analysis. Interface with GCMS for further quantitative analysis post LIF analysis is also possible, due to the non-destructive nature of the fluorescence measurement. The method is being further optimized, and may find application in a centralized environmental laboratory for the southern African region.

\section{Conclusion}

Currently most analytical technology used in the developing world for environmental purposes, is imported from the developed nations [2]. Significant capacity building is needed, but should be undertaken in the context of the differing requirements of developing countries. Alternative organic air pollutant monitoring strategies, such as the use of passive samplers and screening methods, or the monitoring of indicator compounds, have the potential to provide viable, cost effective alternatives to established methods in southern Africa.

\section{References}

[1] Mmolawa, M.D., Scoping report on existing monitoring activities in the 7 APINA member countries, Issued as part of Phase III Activity 2.3 of the RAPIDC Programme 2005-07, Botswana, 2006.

[2] Hight, J. \& Ferrier G., The impact of monitoring equipment on air quality management capacity in developing countries, Organisation for Economic Co-operation and Development, Joint Working Party on Trade and Environment, Report COM/ENV/TD(2006)7/FINAL, 2006.

[3] Air Pollution Information Network for Africa (APINA), www.sei.se/rapidc/apina.htm

[4] Southern and Eastern Africa Network of Analytical Chemists (SEANAC), www.seanac.org

[5] Scholes, R.J. \& Biggs, R. (eds), Ecosystem services in Southern Africa: A regional assessment, CSIR, Pretoria, South Africa, ISBN 0-7988-5527-4, pp. 55, 2004.

[6] Scholes, R., Regional Implementation Plan for Southern Africa, Global Terrestrial Observing System GTOS-21, CSIR internal report ENV-P-R 2001-002, South Africa, February 2001.

[7] Department of Tourism, Environment and Culture, Republic of Lesotho, Environment Act, 2001 Online. www.faolex.fao.org/faolex 
[8] Namibia Directorate of Environmental Affairs, www.met.gov.na/dea

[9] Department of Environmental Affairs and Tourism, South Africa, National Environmental Management: Air Quality Act, 2004, Government Notice No. 528, Government Gazette No. 28899, 9 June 2006.

[10] Department of Environmental Affairs and Tourism, South Africa, Technical Compilation to inform the Initial State of Air Report, National Air Quality Management Programme, May 2007.

[11] Brunke, E.-G., Labuschagne, C. \& Scheel, H.E., Trace gas variations at Cape Point, South Africa, during May 1997 following a regional biomass burning episode. Atmospheric Environment, 35, pp. 777-786, 2001.

[12] Pone, J.D.N., Hein, K.A.A., Stracher, G.B., Annegarn, H.J., Finkleman, R.B., Blake, D.R., McCormack, J.K. \& Schroeder, P., The spontaneous combustion of coal and its by-products in the Witbank and Sasolburg coalfields of South Africa. International Journal of Coal Geology, 72, pp. 124-140, 2007.

[13] Burger, J.W., Pienaar, J.J., Fourie, L. \& Jordaan, J.H.L., Identification of volatile organic compounds in Cape Town brown haze. Air Pollution 2004, WIT Press, UK, pp. 631-640, 2004.

[14] Ortner, E.K. \& Rohwer, E.R., Trace analysis of semi-volatile organic air pollutants using thick film silicone rubber traps with capillary gas chromatography. Journal of High Resolution Chromatography, 19, pp. 339-344, 1996.

[15] Burger, B.V., Marx, B., le Roux, M. \& Burger, W.J.G., Simplified analysis of organic compounds in headspace and aqueous samples by high-capacity sample enrichment probe. Journal of Chromatography A, 1121, pp. 259267, 2006.

[16] Burger, B.V., Snyman, T., Burger, W.J.G. \& van Rooyen, W.F., Thermal modulator array for analyte modulation and comprehensive twodimensional gas chromatography. Journal of Separation Science, 26(1-2), pp. 123-128, 2003.

[17] Department of Tourism, Environment and Communications, Swaziland, Air Pollution Control Regulations, 1999 Online. www.ecs.co.sz

[18] Gachanja, A.N. \& Worsfold, P.J., Monitoring of polycyclic aromatic hydrocarbon emissions from biomass combustion in Kenya using liquid chromatography with fluorescence detection. Science of the Total Environment, 138, pp. 77-89, 1993.

[19] Torto, N., Mmualefe, L.C., Mwatseteza, J.F., Nkoane, B., Chimuka, L., Nindi, M.M. \& Ogunfowokan, A.O., Sample preparation for chromatography: An African perspective. Journal of Chromatography A, 1153, pp. 1-13, 2007.

[20] Ogunfowokan, A.O., Asubiojo, O.I. \& Fatoki, O.S., Isolation and determination of polycyclic aromatic hydrocarbons in surface runoff and sediments. Water, Air, and Soil Pollution, 147, pp. 245-261, 2003.

[21] United Nations Environmental Programme, Stockholm Convention on Persistent Organic Pollutants (POPs), Compilation of existing national 
monitoring programmes, activities and datasets, Document UNEP/POPS/GMP/TWG-2/6, Geneva, 2007.

[22] Batterman, S., Chernyak, S., Gounden, Y. \& Matooane, M., Concentrations of persistent organic pollutants in ambient air in Durban, South Africa. Organohalogen Compounds, 68, pp.1111-1114, 2006.

[23] Lindesay, J.A., Andreae M.O., Goldammer, J.G., Harris, G., Annegarn, H.J., Garstang, M., Scholes, R.J. \& van Wilgen, B.W., International Geosphere-Biosphere Programme/International Global Atmospheric Chemistry SAFARI-92 field experiment: Background and overview. Journal of Geophysical Research, 101(D19), pp. 23521-23530, 1996.

[24] Swap, R.J., Annegarn, H.J., Suttles, T., King, M.D., Platnick, S., Privette, J.L. \& Scholes, R.J., Africa burning: A thematic analysis of the Southern African Regional Science Initiative (SAFARI 2000). Journal of Geophysical Research, 108(D13), pp. SAF 1-1 - 1-15, 2003.

[25] Seethapathy, S., Górecki, T. \& Li, X., Review: Passive sampling in environmental analysis. Journal of Chromatography A, 1184, pp. 234-253, 2008.

[26] Shoeib, M. \& Harner, T., Characterization and comparison of three passive air samplers for persistent organic pollutants. Environmental Science and Technology, 36, pp. 4142-4151, 2002.

[27] Jaward, F.M., Farrar, N.J., Harner, T., Sweetman, A.J. \& Jones, K.C., Passive air sampling of PCBs, PBDEs, and organochlorine pesticides across Europe. Environmental Science and Technology, 38, pp. 34-41, 2004.

[28] John, J., Research to quantify atmospheric volatile organic compounds in the major metropolitan areas of South Africa, CSIR internal report ENV-PC-98016, South Africa, January 1998.

[29] Wichmann, J., Human health risk assessment case study - value addition of passive sampler generated data, CSIR internal report ENV-P-I-99008, South Africa, October 1999.

[30] Kaune, A., Lenoir, D., Schramm, K-W., Zimmermann, R., Kettrup, A., Jaeger, K., Rückel, H.G. \& Frank, F., Chlorobenzenes and chlorophenols as indicator parameters for chlorinated dibenzodioxins and dibenzofurans in incineration processes: influences of various facilities and sampling points. Environmental Engineering Science, 15(1), pp. 85-95, 1998. 